DOI: $10.17805 /$ zpu.2015.4.17

\author{
Семейное образование \\ как вариативная форма обучения \\ И. В. КОЩИЕНКО, Л. И. ПОКРОВСКАЯ \\ (МОСКОВСКИЙ ГУМАНИТАРНЫЙ УНИВЕРСИТЕТ)
}

В статье анализируются усиливающаяся тенденция обучения детей в форме семейного образования в России, его возможности и практики функционирования.

Семейное образование определяется как вариативная форма обучения ребенка, основанная на желании родителей (законных представителей) дать своему ребенку образование в семье. При семейном обучении у родителей есть возможность учитывать индивидуальные особенности своего ребенка, его особые образовательные потребности, нормировать ежедневные учебные нагрузки, составляя график обучения и режим занятий, отвечающий возможностям учащегося. Обучение ребенка в семье позволяет также родителям контролировать качество и количество поступающей к ребенку информации, производить отбор учебных материалов, основываясь на собственных предпочтениях, квалификации и познавательных запросах ребенка. При этом родители имеют возможность выбирать методы подачи материала в зависимости от ведущих типов восприятия информации ребенком (аудиальный, визуальный, кинестетический, дискретный).

Авторы полагают, что специфика обучения ребенка в форме семейного образования заключается в возможности вырабатывать у родителей и их детей познавательно-активный жизненный стиль, который отвечает потребностям современного общества.

Исследование показало, что роль родителей в семейном образовании не в том, чтобы заменить учителей-предметников, а в том, чтобы так организовать процесс обучения, подобрать методы и педагогические технологии, чтобы образование ребенка было качественным, а количество затраченных им и родителями ресурсов - минимальным. В этой связи использование возможностей семейного образования представляется весьма актуальным.

Ключевые слова: современное образование в России; семейное образование; домашнее обучение; надомное обучение

\title{
ВВЕАЕНИЕ
}

$\mathrm{B}$ настоящее время довольно часто возникают разночтения в понятиях, используемых для обозначения обучения вне образовательных учреждений. Это обусловлено разницей в терминологии, существующей в различных странах.

Термин bomeschooling - обучение детей дома (без участия школы), которым оперируют в англоязычных странах (Illich, 1970; Holt, 1999), используется россиянами наравне с термином «семейное образование» для обозначения одного и того же процесса. Однако домашнее обучение в Российской Федерации могло осуществляться по двум причинам: по медицинским показаниям либо по желанию родителей. И сам процесс обучения, и документальное его сопровождение для этих двух вариантов различались.

Целью статьи является рассмотрение проблем правового регулирования семейного образования, раскрытие особенностей обучения в форме семейного образования и перспектив его распространенности в России.

\section{ОСОБЕННОСТИ СЕМЕЙНОГО ОБРАЗОВАНИЯ}

Обучение на дому (надомное обучение) предназначалось для детей, имеющих заболевания, перечисленные в тексте Письма Министерства здравоохранения РСФСР от 28 июля 1980 г. № 17-13-186. В г. Москве обучение на дому согласно ст. 7 Закона «Об образовании лиц с ограниченными возможностями здоровья» предусмотрено Аля детей по состоянию здоровья, не имевших возможность посещать общеобразова- 
тельные учреждения (Закон г. Москвы ... , 2010: Электронный ресурс). На данный момент надомного обучения практически не осталось. Причиной стала реорганизация образовательных организаций путем их слияния, а также политика инклюзии, изложенная в п. 3 ст. 2 Закона г. Москвы «Об образовании лиц с ограниченными возможностями здоровья» 2010 г. (в ред. от 25.06.2014): «...совместное обучение (воспитание), включая организацию совместных учебных занятий, досуга, различных видов дополнительного образования, лиц с ограниченными возможностями здоровья и лиц, не имеющих таких ограничений» (там же).

Термин «домашнее образование» все еще воспринимается обществом именно как образование детей с ограниченными возможностями здоровья.

В отличие от надомного обучения для оформления учащегося на обучение в форме семейного образования, как гласит п. 3.2 ст. 44 Федерального закона «Об образовании в Российской Федерации», достаточным является желание родителей (законных представителей) дать своему ребенку образование в семье (Федеральный закон «Об образовании ..., 2014: 41).

При обучении ребенка в семье у родителей есть возможность учитывать индивидуальные особенности своего ребенка, его особые образовательные потребности, нормировать ежедневные учебные нагрузки, составляя график обучения и режим занятий, отвечающий возможностям учащегося. «Сегодня главное - научить самостоятельно учиться, - пишет $\Lambda$. Петрановская, - а этого и старая школа не умела, и новая пока только пробует» (Петрановская, 2000: Электронный ресурс). Кроме того, обучение ребенка в семье позволяет родителям контролировать качество и количество поступающей к ребенку информации, производить отбор учебных материалов, основываясь на собственных предпочтениях, своем образовательном уровне и познавательных запросах ребенка. При этом родители имеют возможность выбирать методы подачи материала в зависимости от ведущих типов восприятия информации ребенком (аудиальный, визуальный, кинестетический, дискретный) (Величковский и др., 1973).

Подобный подход возможен лишь при условии, что ответственность за уровень образования ребенка добровольно принимают на себя его родители. Ответственность родителей (законных представителей) за получение детьми общего образования закреплена законодательно - согласно п. 4.1 и 6 ст. 44 Федерального закона «Об образовании в Российской Федерации» 2014 г. (Федеральный закон «Об образовании ..., 2014: 41). Общеобразовательная организация при этом несет ответственность лишь за качество проведения промежуточной и итоговой аттестации.

Однако семейное образование все же не является полностью отделенным от государственной образовательной системы: государство предъявляет определенные требования к любой форме образования. Все формы образования в Российской Федерации должны соответствовать требованиям федерального государственного стандарта (далее - ФГОС), в том числе если ребенок учится вне школы. Контроль соответствия получаемого в семье образования требованиям ФГОС осуществляют аккредитованные государством учебные заведения (общеобразовательные школы, центры).

При этом если ежегодные промежуточные аттестации разрешено проходить с использованием удаленных технологий и серверов дистанционного обучения, то ОГЭ и ЕГЭ сдаются исключительно очно - так же, как и обычными школьниками. Аттестат о среднем общем образовании, выдаваемый детям, получившим семейное образование, ничем не отличается от аттестата, который получают учащиеся по традиционной системе. 
Наряду с возможностью учитывать при обучении индивидуальные особенности ребенка (медленное усвоение материала, низкая концентрация внимания или быстрое восприятие материала и т. п.) обучение в форме семейного образования имеет ряд особенностей.

Во-первых, родители могут корректировать программу школьного образования.

Во-вторых, родители сами планируют учебную нагрузку, режим занятий, уделяя максимум времени профессиональной, дополнительной деятельности ребенка (спорт, танцы, музыка и т. А.), поскольку режим семейного обучения как нельзя лучше приспособлен для поездок на соревнования, турниры, выступления.

B-третьих, обучение в форме семейного образования позволяет учащемуся легко приспосабливаться к часто меняющейся специфике школьных требований, если из-за характера работы родителей ребенку приходится менять не только место проживания, но и школы, а значит - коллектив одноклассников и учителей.

B-четвертых, одновременно происходит процесс обучения родителей (большинство из которых не имеют педагогического образования) и их детей.

Специфика обучения ребенка в форме семейного образования заключается в возможности вырабатывать у родителей и их детей познавательно-активный жизненный стиль, который отвечает потребностям современного общества.

Многих педагогов-практиков, а также родителей детей, обучающихся в общеобразовательных организациях, беспокоит, что семейное образование не может способствовать достижению учащимися установленного стандарта образования, так как, например, родители в своем большинстве не являются педагогами и тем более - педагогами-предметниками (Плюсы и минусы ... : Электронный ресурс). Однако в своем диссертационном исследовании А. Я. Якунина подчеркивает, что «многие родители $(70 \%)$ фактически уже осуществляют обучение детей по ряду предметов на дому (объясняют детям непонятный материал, помогают делать домашние задания, приглашают репетиторов и так далее)» (Якунина, 2014: 93). При этом родителям, выбирающим семейное образование, не обязательно обучать детей самим - они имеют возможность обучать своих детей с привлечением репетиторов-предметников, тьюторов, педагогов-психологов, а также посредством создания «семейных школ», в которых родители помогают учить детей друг друга. Тем самым роль родителей в семейном образовании не в том, чтобы заменить учителей-предметников, а в том, чтобы так организовать процесс обучения, подобрать методы и педагогические технологии, чтобы образование ребенка было качественным, а количество затраченных им и родителями ресурсов - минимальным. Поэтому достаточно быть родителем, заинтересованным в развитии и обучении своих детей, готовым вместе с ними учиться и преодолевать трудности.

Еще одна проблема, которая беспокоит специалистов: вне школы ребенок не сможет получить необходимые для жизни социальные навыки.

Отметим, что обучающиеся в семье дети имеют гораздо больше свободного от учебы времени, и это время они проводят в кружках и секциях (т. е. в коллективе сверстников и взрослых), в поездках, прогулках с семьей и с друзьями.

Мы согласны с мнением педагога-практика И. М. Чапковского, что «цель семейного обучения - дать хорошее образование за счет индивидуального подхода. Он учитывает многообразие личных особенностей ученика и при этом сохраняет естественный для здорового ребенка интерес к познанию мира» (цит. по: Боков, 2013: Электронный ресурс). 
РАСПРОСТРАНЕННОСТЬ СЕМЕЙНОГО ОБРАЗОВАНИЯ В РОССИИ

С 2007 г. интерес российских граждан к семейному образованию значительно вырос. Согласно данным Минобрнауки около 100 тысяч семей в России ежегодно переводят детей на семейное обучение. По данным конца 2013 г., опыт семейного обучения получили уже свыше полутора миллионов россиян (Ивойлова, 2013: Электронный ресурс).

Тому, что все большее количество семей (как в России, так и в других странах) сегодня выбирают семейное образование, способствует, в том числе, развитие дистанционного обучения, связанное напрямую с прогрессирующим развитием информационных технологий.

Согласно ч. 2 ст. 16 Федерального закона «Об образовании в Российской Федерации» как процесс обучения, так и прохождение промежуточных аттестаций может осуществляться дистанционно, при помощи сети Интернет. Кроме того, дистанционно пройти промежуточную аттестацию можно и без использования сети Интернет при помощи почтовой связи. Такую технологию дистанционного контроля усвоения знаний детьми, обучающимися в форме семейного образования, практикует, в частности, общеобразовательная школа ГБОУ СОШ № 277 Кировского района г. Санкт-Петербурга, если заключить с этой школой договор без посредника. В таком случае аттестации по каждому предмету проводятся два раза в год.

Интересную образовательную услугу предоставляет «Международная школа завтрашнего дня» г. Москвы (Образование в семье: Электронный ресурс). В этой образовательной организации можно пройти билингвальное обучение, когда каждый предмет изучается параллельно на двух языках: русском и английском. По завершении обучения выпускники получают два документа: российский аттестат о среднем общем образовании и диплом американского образца, что позволяет продолжить обучение как в России, так и за рубежом. При этом обучение может происходить по желанию обучающегося и его родителей (законных представителей) как очно, так и дистанционно. Итоговые государственные аттестации сдаются очно, как того требует Федеральный закон «Об образовании в Российской Федерации», а вместо промежуточных аттестаций дети пишут ежемесячные контрольные работы, на основании которых в конце года школа ставит годовую отметку.

Более комфортные условия для реализации семейного обучения в настоящее время имеются в так называемых альтернативных школах. В таких школах обучаются дети, числящиеся на семейной форме обучения и проходящие ежегодные аттестации в имеющих лицензию общеобразовательных организациях. Альтернативные школы чаще всего создаются родителями детей, обучающихся в форме семейного образования. Поначалу родители кооперируются для обучения своих детей, впоследствии набирают учеников «со стороны». Поскольку финансовые затраты на аренду помещения, покупку необходимой мебели и компьютерной техники, учебных пособий и материалов достаточно велики, стоимость обучения получается довольно высокой.

Аля сдачи ежегодных аттестаций дети, обучающиеся в альтернативных школах, прикрепляются к любой образовательной организации на свой выбор либо на выбор альтернативной школы. Большинство таких школ осуществляют образовательный процесс, опираясь на альтернативные программы обучения.

Наиболее известны в Москве на данный момент следующие альтернативные школы: «Золотой ключик», «Земляне», центр семейной культуры «Теремок», «Ирис», «Семейкин клуб», «Муми-школа», клубная школа «Большая черепаха», семейный 
клуб-школа «Бюллербю», пространство альтернативного обучения «Сфера». Подобные школы есть и в Московской области.

Сложность обучения в альтернативной школе, как правило, заключается в несоответствии используемой школой программы программе образовательной организации, в которой обучающиеся в форме семейного образования дети проходят аттестацию.

Существуют также так называемые школы одного дня на базе частной школы, куда дети, обучающиеся в форме семейного образования, приходят на занятия один раз в неделю, а остальное время учатся дома. Аттестация, как правило, проходит очно в этой же школе. Наиболее известная школа одного дня - лицей «Ковчег XXI». Однако согласно опросу, проведенному в «Живом Журнале» в 2015 г., большинство детей, обучающихся в форме семейного образования, не посещает альтернативные школы или школы одного дня (79\% - учатся дома; 14,8\% - привлекают репетиторов; 6,2\% - учатся в альтернативной школе).

\section{ЗАКАЮЧЕНИЕ}

На современном этапе развития образования практически любую информацию можно найти в библиотеке или в Интернете. Во Всемирной сети существует более 9000 научных блогов, а значит, есть возможность выбрать, какие из них читать. Сотни приложений позволяют проводить онлайн-занятия (у обучающихся есть возможность обсуждать интересующие их темы с единомышленниками, задавать вопросы, получать ответы, нарабатывать опыт исследовательской деятельности). В Интернете размещены обучающие видеоролики по темам любых школьных предметов (например, сайт «Уроки школьной программы. Видео, конспекты, тесты, тренажеры», расположенный по адресу interneturok.ru). Консультацию преподавателей по любым предметам можно получить не только очно, но и через Интернет с помощью программ онлайн-общения, например, Skype.

В этой связи использование возможностей семейного образования представляется весьма актуальным, так как:

- основной целью перехода от образования в общеобразовательной организации к обучению в семье является повышение качества получаемого образования; средством достижения этой цели является индивидуальный подход во всем, что так или иначе связано с содержанием и организацией процесса обучения;

- основная задача семейного образования состоит в том, чтобы, используя современные әффективные педагогические технологии, дать ребенку не количественную, а качественную оценку его работы; обеспечить развитие познавательного интереса и познавательной активности ребенка;

- одной из задач семейного образования является постепенное развитие в ребенке способности к самообразованию и самостоятельному обучению;

- важным моментом является постоянное обучение ребенка собственным примером, поскольку собственный пример является лучшим учителем (если у родителей есть тяга к получению новых знаний, велика вероятность, что ребенок и сам будет с удовольствием учиться).

\section{СПИСОК АИТЕРАТУРЫ}

Боков, М. (2013) Семейное образование - закрыть нельзя продолжать [Электронный ресурс]// Pravmir.ru. Православие и мир. 7 октября. URL: http://pravmir.ru/semejnoe-obrazovanie-est-li-budushhee-1/ [архивировано в WebCite] (дата обращения: 12.08.2015). 
Величковский, Б. М., Зинченко, В. П., Аурия, А. Р. (1973) Психология восприятия М. : ИзА-во Моск. ун-та. 245 с.

Закон г. Москвы от 28 апреля 2010 г. № 16 «Об образовании лиц с ограниченными возможностями здоровья в городе Москве» (ред. от 25.06.2014) [Электронный ресурс]// Аепартамент образования города Москвы. URL: http://dogm.mos.ru/legislation/lawacts/874305/ [архивировано в WebCite] (дата обращения: 12.08.2015).

Ивойлова, И. (2013) Минобрнауки разъяснило правила домашнего обучения [Электронный ресурс]// Российская газета. 26 ноября. http://rg.ru/2013/11/26/obrazovanie-site.html [архивировано в WebCite] (дата обращения: 12.08.2015).

Образование в семье [Электронный ресурс] // Международная школа завтрашнего дня. URL: http://schooloftomorrow.ru/studyhome/ [архивировано в WebCite] (дата обращения: 12.08.2015).

Петрановская, $\Lambda$. (2000) Аве тенденции в образовании (Аоклад на конференции «Рубеж 2000 », посвященной прогнозам развития в XXI веке различных сторон жизни человечества) [Электронный ресурс] // Русский язык. № 33. URL: http://rus.1september.ru/article.php?ID= 200003301 [архивировано в WebCite] (дата обращения: 12.08.2015).

Плюсы и минусы домашнего обучения [Электронный ресурс]// Центр домашнего обучения. URL: http://school4you.ru/pliusy-i-minusy-domashnego-obucheniia [архивировано в WebCite] (дата обращения: 12.08.2015).

Федеральный закон «Об образовании в Российской Федерации». По сост. на 2014 г., с коммент. юристов. (2014) М. : Эксмо. 800 с.

Якунина, А. Н. (2014) Педагогические условия становления семейного образования в России: культурно-исторический подход : дис. ... канд. психол. наук. М. 208 с.

Holt, J. (1999) Growing without schooling. Cambridge, MA : Holt Associates. 262 p.

Illich, I. (1970) Deschooling society. N. Y. : Harper \& Row. 186 p.

Aата поступления: 3.09.2015 г.

\section{HOMESCHOOLING (EDUCATION IN THE FAMILY) \\ AS AN EDUCATIONAL OPTION \\ I. V. KOSHCHIENKo, L. I. POKROVSKaya \\ (MOSCOW UNIVERSITY FOR THE HUMANITIES)}

The article examines the rising trend of educating children at home in Russia, its capabilities and existing practices.

Homeschooling can be defined as an optional form of learning, activated at the request of the child's parents (or legal representatives) to give their children education at home. By using this option, parents have the opportunity to tailor learning to individual characteristics of their children, or their special educational needs. By setting up a learning timetable and learning mode, parents can normalize the daily training load and make it meet the capabilities of the student. Homeschooling also allows parents to monitor the quality and quantity of the information the child consumes, to carefully select teaching materials, fitting them to match their own preferences, as well as the qualifications and educational needs of their child. In addition, parents get an opportunity to choose how to present the material to the child by deploying the basic perception types (auditory / visual/ kinesthetic/ discrete).

We see the specificity of homeschooling (education within the family) lies in in its power to help parents and their children build a cognitively active lifestyle that meets the needs of modern society.

Our study has shown that the role of parents in homeschooling is not to replace the teacher, but to organize the process of learning, select methods and educational technologies in order to produce the best results for their child with minimal resources spent. In this regard, homeschooling and its educational promises are most relevant.

Keywords: modern education in Russia; education in the family; homeschooling 


\section{REFERENCES}

Bokov, M. (2013) Semeinoe obrazovanie - zakryt' nel'zia prodolzhat' [Homeschooling - cease or continue?]. Pravmir.ru. Pravoslavie i mir. October 7. [online] Available at: http://pravmir.ru/ semejnoe-obrazovanie-est-li-budushhee-1/ [archived in WebCite] (accessed 12.08.2015). (In Russ.).

Velichkovskii, B. M., Zinchenko, V. P. and Luriia, A. R. (1973) Psikbologiia vospriiatiia [The psychology of perception]. Moscow, Moscow University Publ. 245 p. (In Russ.).

Zakon g. Moskvy ot 28 aprelia 2010 g. № 16 «Ob obrazovanii lits s ogranichennymi vozmozhnostiami zdorov'ia v gorode Moskve» (red. ot 25.06.2014) [Municipal law of the City of Moscow "On Education for People with Health Limitation in Moscow" No. 16, of April 28, 2010 (as amended on June 25, 2014)]. Departament obrazovaniia goroda Moskvy [online] Available at: http://dogm. mos.ru/legislation/lawacts/874305/ [archived in WebCite] (accessed 12.08.2015). (In Russ.).

Ivoilova, I. (2013) Minobrnauki raz»iasnilo pravila domashnego obucheniia [Ministry for Education and Science explains homeschooling rules]. Rossiiskaia gazeta, November 26. [online] Available at: http://rg.ru/2013/11/26/obrazovanie-site.html [archived in WebCite] (accessed 12.08.2015). (In Russ.).

Obrazovanie v sem'e [Education in the family]. Mezbdunarodnaia shkola zavtrashnego dnia [online] Available at: http://schooloftomorrow.ru/studyhome/ [archived in WebCite] (accessed 12.08.2015). (In Russ.).

Petranovskaia, L. (2000) Dve tendentsii v obrazovanii (Doklad na konferentsii «Rubezh 2000», posviashchennoi prognozam razvitiia v XXI veke razlichnykh storon zhizni chelovechestva) [Two trends in education (A paper presented at the Rubezh 2000 conference on the possible development of various aspects of the humanity in the 21st century)]. Russkii iazyk, no. 33. [online] Available at: http://rus.1september.ru/article.php?ID=200003301 [archived in WebCite] (accessed 12.08.2015). (In Russ.).

Pliusy i minusy domashnego obucheniia [The advantages and disadvantages of homeschooling]. Tsentr domashnego obucheniia [online] Available at: http://school4you.ru/pliusy-i-minusy-domashnego-obucheniia [archived in WebCite] (accessed 12.08.2015). (In Russ.).

Federal' nyi zakon "Ob obrazovanii v Rossiiskoi Federatsii" : po sostoianiiu na 2014 g. : s kommentariiami iuristov [Federal Law 'On education in the Russian Federation', as of 2014, with lawyers' comments]. (2014) Moscow, Eksmo Publ. 800 p. (In Russ.).

Iakunina, A. N. (2014) Pedagogicheskie usloviia stanovleniia semeinogo obrazovaniia $v$ Rossii: kul'turno-istoricheskii podkbod [Pedagogical requirements for the rise of homeschooling in Russia: A cultural and historical approach] : Diss. ... Candidate of Psychology. Moscow. 208 p. (In Russ.).

Holt, J. (1999) Growing without schooling. Cambridge, MA, Holt Associates. 262 p.

Illich, I. (1970) Deschooling society. New York, Harper \& Row. 186 p.

Submission date: 3.09.2015.

Кощиенко Ирина Васильевна - кандидат педагогических наук, доцент кафедры педагогики и психологии высшей школы Московского гуманитарного университета. Адрес: 111395, Россия, г. Москва, ул. Юности, д. 5. Тел.: +7 (499) 374-70-53. Эл. адрес: ds2723@mail.ru

Покровская Аариса Игоревна - бакалавр кафедры педагогики и психологии высшей школы Московского гуманитарного университета. Адрес: 111395, Россия, г. Москва, ул. Юности, А. 5. Тел.: +7 (499) 374-56-11. Эл. адрес: larapokrovckaya@gmail.com. Научный руководитель канд. пед. наук И. В. Кощиенко.

Koshchienko Irina Vasilievna, Candidate of Pedagogy, Associate Professor, Department of Pedagogy and Psychology of Higher School, Moscow University for the Humanities. Postal address: 5 Yunosti St., 111395 Moscow, Russian Federation. Tel.: +7 (499) 683-59-30.E-mail: ds2723@mail.ru

Pokrovskaya Larisa Igorevna, Unergraduate, Department of Pedagogy and Psychology of Higher School, Moscow University for the Humanities. Postal address: 5 Yunosti St., 111395 Moscow, Russian Federation. Tel.: +7 (499) 374-56-11. E-mail: larapokrovckaya@gmail.com. Research advisor: Candidate of Pedagogy I. V. Koshchienko. 